\title{
MEDEIA. DA AFIRMAÇÃO DO HUMANO À NEGAÇÃO DO DIVINO
}

\author{
MEDEA. FROM THE AFFIRMATION OF THE HUMAN TO THE DENIAL OF THE DIVINE
}

Thais Luz Resende Gonçalves*

\section{RESUMO}

A pesquisa que comunicamos apresenta uma leitura da peça trágica Medeia, escrita pelo poeta Eurípides em 431 a.C., considerando a possibilidade que encontramos de múltiplas faces da personagem Medeia, marcadas por tensões que culminam na realização da peripécia conceito extraído da Poética de Aristóteles. A peripécia, por sua vez, é interpretada dialeticamente, de modo a mostrar a originalidade de Eurípides. O prólogo do texto funciona como uma grande didascália, apresentando, portanto, essas faces de Medeia previamente anunciadas. Diante das faces que Medeia assume constituem-se figuras que identificamos como uma tríplice ambiguidade, quais sejam: Medeia transitando entre a passionalidade e a racionalidade, entre mulher bárbara e grega e a maior e mais importante ambiguidade, Medeia entre a figura humana e a figura divina. Sob essa perspectiva propomos que a construção da personagem Medeia é um expediente dialético.

\section{ABSTRACT}

The research we communicate presents a possibility of reading the tragic play Medeia, written by the poet Eurípides in $431 \mathrm{BC}$, considering the possibility that we find of reading multiple faces of the character Medeia, marked by tensions that culminate in the realization of the adventure - a concept extracted from Poetics of Aristotle. Peripecia, in turn, is interpreted dialectically, in order to show the originality of Euripides. The prologue of the text works as a great didascálica presenting, therefore, these faces of Medeia previously announced. Facing the faces that Medeia assumes, the following figures are identified as a triple ambiguity, namely: Medeia transiting between passionality and rationality, between barbarian and Greek woman and the greatest and most important ambiguity, Medeia between the human figure and the figure divine. From this perspective, we propose that the construction of the character Medeia is a dialectic expedient.

\section{INTRODUÇÃO}

A tragédia grega foi o maior movimento artístico da antiguidade clássica. Durante cem anos de história viveu a sua efervescência na cultura grega e produziu inúmeros textos cênicos que deram origem ao teatro ocidental. Os tragediógrafos, poetas responsáveis pela escrita dos textos, contam a história de um povo através de sua narrativa mitológica. A mitologia é uma

\footnotetext{
* Graduação em filosofia pela PUC Minas. E-mail: thluzresende@yahoo.com.
} 
grande fonte histórica para qualquer pesquisador que pretenda se deter sob a estrutura de vida de uma época, de uma cultura.

Dentro da literatura clássica, a tragédia grega parece dialogar com diversos campos do conhecimento, motivo pelo qual as pesquisas que tratam desse tema podem ser enriquecidas por ter em seu horizonte um campo aberto de possibilidades e de dados a serem trabalhados. Nesta pesquisa optamos por aproximar a tragédia especialmente da filosofia, usando principalmente da dialética, estrutura própria da filosofia, para alcançar tal objetivo. Além disso usaremos filósofos que pensaram a tragédia, dentro de sua filosofia, para aprofundar no tema.

Nosso recorte é a peça Medeia escrita por Eurípides em 431 a.C., que conta a história de uma feiticeira que, ao ser traída pelo marido, elabora e executa um plano de vingança. Ao longo da peça conseguimos perceber uma série de temas de extrema atualidade, sobretudo em relação à enigmática figura de Medeia. Os discursos de Medeia são impressionantes dentro de seus limites históricos, a personagem discute, por exemplo, sobre o lugar da mulher na sociedade e na vida familiar, tema que ainda hoje é muito caro à nossa sociedade. Embora a protagonista da peça (Medeia) tenha suscitado diversos e importantes estudos, a complexidade do fazer poético de Eurípides nessa peça ainda desafia pesquisadores e diante disso vemos a possibilidade de explorar nesta pesquisa pontos ainda relevantes na obra.

A pesquisa pretende entender a complexidade da construção da personagem Medeia por meio de suas ambiguidades internas e de uma possível estrutura dialética presente nessa construção. Pensar a personagem Medeia na contemporaneidade pode parecer ultrapassado em certa medida, mas não podemos negar que a feiticeira infanticida ainda hoje é uma personagem mitológica extremamente complexa, de grande magnitude filosófica e psicológica. Medeia aparece todos os dias nos noticiários, estampada no rosto de homens e mulheres que, em nome de uma paixão (pathos) desmedida e doentia, se veem no lugar de direito de vingança e matam simplesmente, movidos pelo ódio que se mascara no amor. Pensar Medeia hoje é, portanto, pensar no impacto que sua figura causou no Ocidente e como depois de quase 2500 anos ainda vemos histórias parecidas com a sua se repetirem todos os dias.

A cultura ocidental é grega na sua gênese e, de certa forma, em muitos dos seus desdobramentos. Quer dizer que nossa relação com os gregos não deve ser caracterizada pela oposição e pela pretensão de tomá-los como mero objeto. Trata-se, antes, da exigência de nos pensarmos a partir da cultura dos helenos. De acordo com Leão (2002, p. 30), 
nossa cultura, no ufanismo de seu próprio pensamento, tem preferido, ao longo dos séculos, quando não pensar contra os outros, simplesmente pensar os outros, o que implica tomá-los como objeto e não como parceiros com os quais, necessariamente, se deve estabelecer uma relação de lateralidade e mutualidade.

Trata-se de pensar com os gregos, o que implica a superação de uma postura acadêmica que os reduz à figura de um outro, portanto, estranho ao nosso modo de ver o mundo. Para Brandão (2002, p. 31), “antes de mais nada, é preciso observar que, quando imaginamos que estamos pensando sozinhos, estamos, no fundo, pensando com eles”.

Quando se trata do povo helênico, numerosos traços contribuíram para que toda a história fosse, em certa medida, marcada por sua presença e para que estudiosos como Nietzsche os considerassem "a mais bem-sucedida, a mais bela, a mais invejada espécie de pessoas até agora [...]”. É claro que o traço mais reconhecidamente helênico que permeia a cosmovisão ocidental é a filosofia.

Contudo, para além da gênese da filosofia ocidental, os gregos são também responsáveis pela riqueza no campo das artes, de modo que suas contribuições estéticas possuem, em algum grau, um alcance ainda hoje, por vezes influenciando no nosso juízo acerca daquilo que pode ser considerado arte.

Entre as diversas formas de arte que possuem sua gênese na Grécia - sobretudo na passagem do século VI para o século V a.C. - é o teatro, especialmente o gênero trágico (o primeiro gênero teatral que surgiu), que é considerado a expressão artística mais fértil, seja para repensar o lugar representado pelo homem grego ou, dado seu magnífico alcance, a condição do ser humano em termos gerais.

É praticamente um consenso entre os estudiosos de Grécia que é o ambiente ritualístico grego que cria o espaço ideal para o advento do teatro. Acredita-se que foi nos cortejos dionisíacos que teria surgido a primeira figura do ator. Segundo Aristóteles (2017) (Poética, 1449a 5 a 10), é o improviso dentro do ritual que propicia o surgimento do intérprete.

A cidade acomoda o rito dionisíaco e o inclui entre os cultos públicos, com isso a formalização do teatro clássico se dá nas Grandes Dionisíacas, festejos a Dioniso que ocorriam em Atenas, com a duração de praticamente uma semana. Nessa ocasião festiva, além de rituais religiosos e dos atos cívicos, tais como premiações a estrangeiros que prestaram serviços relevantes à Polis, desfiles militares, entre outros, havia um espaço destinado ao teatro - na forma de um concurso de tragédias, onde cada tragediógrafo concorrente 
apresentava uma trilogia de peças teatrais (três tragédias e um poema satírico). Tal espaço não era de pouca monta, dada a importância oficial que adquiriu.

O Estado chegou a financiar os poetas trágicos para que estes pudessem se dedicar à escrita e à produção de suas peças durante todo ano para serem apresentadas no concurso do ano seguinte. Entre os múltiplos tragediógrafos que apresentaram suas peças nesse período são Ésquilo (525 a.C - 456 a.C.), Sófocles (497 a.C. - 406 a.C.) e Eurípides (480 a.C - 406 a.C.) os expoentes que conquistaram o maior reconhecimento e escreveram grande parte daquilo que chegou aos nossos dias.

Nas peças de Eurípides o cotidiano ganha espaço cênico, o homem é o protagonista e não mais os deuses, o destino do ser humano não está entregue aos deuses, pois ele mesmo o constrói e o modifica.

É possível atribuir uma separação entre Eurípedes e seus antecessores, Ésquilo e Sófocles, ainda que estejam inseridos no mesmo gênero literário e que, por vezes, tenham até representado o mesmo mito em suas obras (como o exemplo da peça Electra). Eurípedes, no entanto, introduz novos elementos em detrimento de outros. E se, na visada aristotélica, o poeta é merecedor do elogio o "mais trágico entre os trágicos", para Nietzsche o que ocorre é homicídio da arte trágica. ${ }^{1}$

Eurípedes privilegia em sua poética (i) graus de mobilidade existencial de suas personagens, de forma que elas não são postas como resultados da potência divina. O poeta, ainda que não recuse por completo as forças do destino, concede à ação humana uma espécie de liberdade embrionária, configurando um espaço de liberdade que é apontado por Vernant (1988, p. 76) da seguinte maneira:

\begin{abstract}
Nos dramas de Eurípides, o cenário divino perdeu seus contornos ou, em todo caso, se afastou das peripécias humanas. No último dos grandes Trágicos, o foco incide de preferência sobre os caracteres individuais dos protagonistas e sobre suas relações mútuas. Mas, entregue assim a si mesmo, liberto em grande parte do sobrenatural, reduzido à sua dimensão de homem, nem assim o agente aparece nitidamente delineado.
\end{abstract}

O prólogo (ii), por sua vez, é certamente uma das principais inovações do poeta, de modo a gerar no espectador um conhecimento prévio das ações cênicas a serem realizadas.

\footnotetext{
${ }^{1}$ No capitulo onze da obra $O$ nascimento da tragédia podemos encontrar um trecho em que o autor defende tal ideia: "Essa luta com a morte da tragédia foi travada por Eurípides". O teatro de Eurípides escapa aos padrões de seu tempo, dessa forma, Nietzsche descreve a obra euripidiana como a passagem para algo novo, para além da tragédia.
} 
Tal conhecimento (prévio) era o pressuposto comum² a toda representação trágica. Contudo, no caso de Eurípedes o prólogo funciona como didascálias ${ }^{3}$, isto é, indicações cênicas. Vale ressaltar que no texto do teatro grego não há rubricas, não há informações cênicas fora do próprio texto a ser encenado. Quer dizer que é no interior do texto cênico que se pode encontrar aquilo que orienta o ator na construção da cena.

Entre as peças escritas por Eurípides, Medeia é sem dúvidas uma das que mais se destacam, apesar de ter ficado em terceiro lugar do concurso de 431 a.C. Medeia (personagem) marcou definitivamente, com o seu amor assassino e vingativo, a história do teatro grego. Ao longo do prólogo, é possível visualizar esboços de figuras de Medeia, que se apresentam como uma espécie de indicações cênicas. Ao longo da peça, surgem diversas faces de Medeia, desenvolvidas a partir das didascálias veiculadas pelo Prólogo, de modo que é possível perceber como o desenvolvimento do enredo depende do prólogo.

O movimento entre a negação do humano e a afirmação do divino da personagem Medeia nos fez enxergar a possibilidade de pensar a hipótese de um movimento dialético na peça, movimento construído essencialmente pelas ambiguidades da personagem Medeia. A despeito da força e importância dessa concepção - a de que a peça Medeia contém figuras diversas da protagonista - entende-se que é possível propor uma leitura que compreende a peça a partir das ambiguidades de Medeia. Nesse sentido é preciso explicitar o que aqui se entende por dialética.

A dialética aparece em vários momentos da história da filosofia. Em termos gerais, a noção de dialética compreende uma construção que supõe a oposição entre princípios teóricos, sentenças argumentativas ou fenômenos a fim de que a partir dessas oposições/contradições se produza algo novo, sob a figura de uma síntese conciliadora. Associar Medeia a algum dos métodos dialéticos propostos na história da filosofia esbarra em dificuldades anacrônicas e textuais, que sugerem como melhor caminho o abandono dessa hipótese inicial. Contudo, parece razoável admitirmos figuras diversas que compõem a

\footnotetext{
${ }^{2}$ A sociedade grega encontrou na mitologia a possibilidade de explicar o mundo ao seu redor. Através do mito os gregos explicavam, por exemplo, os fenômenos da natureza, acontecimentos do dia a dia e transmitiam ensinamentos. Diante disso podemos afirmar que o caráter mitológico faz parte da estrutura e da formação da cultura grega. Com o nascimento do teatro, diretamente atrelado à narrativa mitológica em torno do deus Dioniso como pudemos ver acima, o público das tragédias gregas já tinha um conhecimento prévio das grandes aventuras e dos heróis mitológicos que eram apresentados nas peças (vale ressaltar que o objeto da tragédia grega é essencialmente o mito), dessa forma o poeta não precisava contar toda a história do personagem, na maioria das vezes os gregos já sabiam todo o enredo da peça, e a intenção de assistir era justamente ver como aquele autor havia colocado tal mito em cena, as técnicas e recursos utilizados.

${ }^{3}$ Vinda do grego - didaskália - essa palavra se refere às indicações de cena que o autor cria para o ator, instruções.
} 
personagem e entendemos como segunda hipótese que essas figuras se opõem de tal maneira que promovem a peripécia.

\section{AMBIGUIDADE E DIALÉTICA DAS FACES DE MEDEIA}

A primeira face ambígua da Medeia consiste na oscilação entre a passionalidade e a racionalidade. No início da peça é a figura de Medeia passional que se apresenta, como fica evidente nos trechos seguintes "seu corpo carpe, inane ela se prostra, delonga o pranto grave assim que sabe o quanto fora injustiçada" e "sua psique circunspecta suporta mal a dor" (EURÍPIDES, 2010, p. 25), em que Medeia não parece possuir em si nada de racional e está

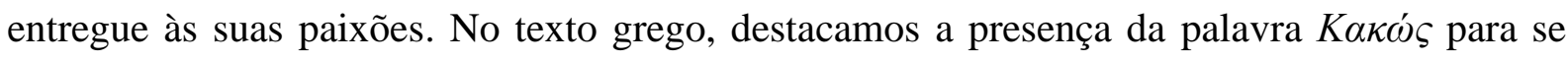

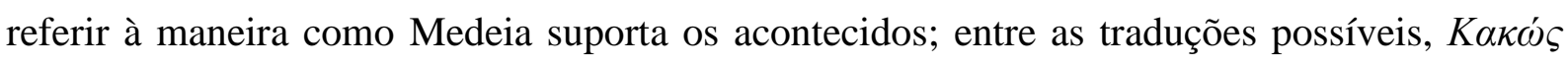
aparece em Pereira (1969) como "com má intenção", o que revela muito sobre o desejo de vingança latente presente em Medeia. Mas é importante ressaltar que intencionalidade já revela o elemento racional, ou seja, Medeia não é puramente passional, assim como também não é puramente racional.

$\mathrm{Na}$ segunda ambiguidade encontramos uma Medeia transitando entre o grego e o bárbaro, a despeito da sua origem Cólquida. Essa compreensão pode ser muito bem demonstrada no texto. É óbvio que Medeia é estrangeira em Corinto, essa questão é levantada nos primeiros versos do prólogo. Mas o que pretendemos apontar é que apesar de estrangeira Medeia tem um discurso próprio dos gregos, característico dos sofistas. A personagem usa de um discurso muito bem articulado para tentar convencer o coro (e também o público) a compactuar com seus planos. Sua habilidade com a fala surpreende Creonte como se evidencia em: "Tua fala é um bálsamo, mas me amedronta que acalentes no peito planos torpes." (EURÍPIDES, 2010, p. 51). A ambiguidade se firma, portanto, no sentido de que Medeia é bárbara, mas também possui habilidade discursiva característica dos gregos.

Finalmente, é perceptível o que, nos limites desta proposta, parece ser a ambiguidade mais importante, qual seja, a possibilidade de câmbio entre o humano e divino. O sofrimento passional não é próprio dos deuses, da mesma forma que a feitiçaria e o triunfo de Medeia não são próprios dos humanos. A proximidade com os deuses é muito presente na ancestralidade de Medeia, sobrinha da feiticeira e deusa Circe e neta do deus Hélios (o Sol), é evidente que Medeia carrega traços de divindade, especialmente a capacidade de feitiçaria herdada de Circe. 
Apesar dessa proximidade com o divino, Medeia não é deusa, pelo menos não no início de sua trajetória; a divindade de Medeia é construída junto com a própria personagem. A isso se deve a grande dificuldade de encontrarmos no prólogo da peça trechos que funcionem como um esboço cênico para a construção da divindade de Medeia. Afirmamos que Medeia assume a sua humanidade quando se estabelece em seu casamento após ter fugido com Jasão. Ora, assumir a humanidade pressupõe que antes disso Medeia não era humana. De fato, em Cólquida é a face da deusa Medeia que se apresenta a Jasão e faz com que, visando os benefícios de ter ao seu lado uma feiticeira, ele a use para atingir seus objetivos de chegar ao trono de Iolcos. Ao se casar com Jasão e se estabelecer em Corinto, onde por um tempo o casal vive sem nenhuma complicação, a personagem nega a sua divindade e assume o papel de humana, se torna mãe, senhora de sua casa e uma esposa apaixonada pelo marido. Medeia se faz tão humana que quando a traição de Jasão acontece ela é dilacerada pela dor que sua humanidade lhe propõe como sugere o texto. Daí por diante a personagem dá início a um processo de negação da humanidade em que se colocou e aos poucos retoma seu lugar divino.

Fica claro, portanto, que o principal movimento da peça é a negação do humano; toda a trajetória de Medeia nos mostra que a feiticeira busca o seu lugar de divindade. Podemos afirmar que todo o processo de vingança de Medeia é também um processo de conquista da divindade. No momento em que Medeia deixa o palco no carro do Sol ela não é mais apenas sua neta feiticeira, ela se eleva à posição de divindade, visto que de acordo com os relatos míticos é no Olimpo que a feiticeira busca refúgio, um humano não ocupa lugar no Olimpo. Levantamos então a hipótese de que toda a construção cênica de Medeia é também a construção de um movimento de negação do humano à afirmação do divino.

Retomamos então a hipótese do movimento dialético. É evidente que existe uma peripécia aos moldes aristotélicos (como vimos), mas o movimento de construção da personagem nos parece ser um movimento muito complexo; seguimos, portanto, na hipótese de que seja um movimento dialético. Testada todas as possibilidades que levantamos anteriormente para o modelo dialético a ser analisado, entendemos que a visada dialética presente na peça Medeia é uma dialética pautada na peripécia, mas superior a ela. Uma dialética originalmente euripidiana.

A dialética euripidiana presente na peça Medeia se constitui em três momentos crescentes: (i) a contraposição das faces racional e passional em que após a luta conflituosa a face racional se sobressai sem eliminar a passionalidade; (ii) a contraposição das faces bárbara e grega em que a solução é muito complexa, Medeia se vê como apátrida, não segue a lei 
grega mas já não se encaixa em lugar nenhum, seu destino final é o Olimpo; (iii) a contraposição das faces divina e humana em que, apesar de sair da peça como deusa, Medeia não é puramente deusa, é um ser híbrido, mesclado de humano e divino. Nesse momento podemos demarcar a grande peripécia da peça, o momento de virada do infortúnio para a fortuna, momento em que a personagem efetiva a sua vingança e sai vitoriosa.

Não temos aqui a estravagante pretensão de esgotar a hipótese da construção de uma dialética euripidiana e entendemos as lacunas deixadas acerca do tema que poderão ser preenchidas em uma pesquisa posterior como, por exemplo, analisar o movimento dialético em outras obras de Eurípides. Mas enxergamos que o caminho construído até aqui é de extrema importância; abrimos a possibilidade de uma nova leitura de Medeia, peça que sempre que é revisitada não perde a atualidade dos fatos; peça que nos revela muito acerca do espírito de um povo mas que, mais do que isso, nos revela muito de nós mesmos, seres humanos frágeis entregues ao eterno conflito entre o intelecto e nossas paixões.

As interpretações sobre a obra e a pessoa de Eurípides são também ambíguas. O poeta, que foi o mais trágico entre trágicos sob o olhar de Aristóteles, em Nietzsche, ele decreta o fim da tragédia. Ele é tão complexo quanto seus próprios personagens e qualquer discurso fechado sobre sua obra corre risco de eliminar as múltiplas possibilidades do autor. A presente pesquisa não esgota o poeta; muito pelo contrário, o que pretendemos é uma nova possibilidade de leitura, um novo olhar sobre a complexidade de Eurípides, e diante da proposta dialética em Eurípides, entendemos que tal proposta foi alcançada por nós.

\section{REFERÊNCIAS}

ARISTÓTELES. Poética. Tradução de Paulo Pinheiro. 2. ed. São Paulo: Editora 34, 2017.

EURÍPIDES. Medeia. Tradução de Trajano Vieira. São Paulo: Editora 34, 2010.

LEÃO, Ângela Vaz et al. Os gregos. Belo Horizonte: Autêntica, 2002.

NIETZSCHE. Friedrich. O nascimento da tragédia ou helenismo e pessimismo. Tradução de J. Guinsburg. São Paulo: Companhia das Letras, 2007.

PEREIRA, Isidro. Dicionário grego-português e português-grego. 4. ed. Porto: Livraria Apostolado da Imprensa, 1969.

VERNANT, Jean-Pierre; VIDAL-NAQUET, Pierre. Esboços da vontade na tragédia grega. In: Mito e tragédia na Grécia antiga. Tradução Anna Lia A. de Almeida Prado. São Paulo: Brasiliense, 1988. 